\title{
LA FAMILIA ANTE LA PANDEMIA DEL COVID-19
}

\author{
CRISTIÁN LEPIN MOLINA \\ Universidad de Chile, Santiago de Chile, Chile \\ Recibido: 12/7/2020 - Aprobado: 19/8/2020 \\ doi: https://doi.org/10.26439/iusetpraxis2020.n50-51.5028
}

\begin{abstract}
RESUMEN. La coyuntura actual gira en torno a las consecuencias que ha traído el COVID-19 para la vida en sociedad. Esta enfermedad ha demostrado ser no solo un aspecto a considerar en la salud o la economía, sino que también tiene implicaciones en la forma en la que nos interrelacionamos y convivimos como seres sociales. El objeto del presente artículo es repasar los efectos que ha generado el COVID-19 y las medidas que se han adoptado para combatirla en el ámbito del derecho civil y, de forma más específica, otorgarle un enfoque al área de familia respecto a los efectos de la pandemia. A lo largo del trabajo analizaremos temas relacionados con las principales trabas para el acceso a la justicia, así como también los cambios en las relaciones personales entre los integrantes de la familia y las implicancias que conlleva la pandemia en materia de pensiones de alimentos.
\end{abstract}

PALABRAS CLAVE: relaciones paterno filiales / pandemia COVID-19 / derecho de familia / pensiones de alimento

\section{THE FAMILY IN THE FACE OF THE COVID-19 PANDEMIC}

ABSTRACT. The current situation revolves around the consequences that COVID-19 has brought for life in society. This has proven not only to be an aspect to consider in health or the economy but also to have implications in the way we interrelate and coexist as social beings. This article aims to review the effects generated by COVID-19 and the measures to combat it in the field of civil law. More specifically, its purpose is to focus on the family regarding the effects of the pandemic. Throughout this work, we will analyze issues related to the main obstacles to access to justice, as well as the changes in personal relationships among family members, and the implications of the pandemic in terms of alimony.

KEYWORDS: parental relationships / COVID-19 pandemic / family law / alimony 


\section{INTRODUCCIÓN}

El coronavirus ha impactado muy fuertemente a Latinoamérica. Países como Chile, Perú y Argentina se han visto especialmente afectados por el nivel de contagio del virus y por las limitaciones a la libertad de los ciudadanos con el objeto de controlar la propagación de aquel. Esto nos lleva a revisar cuáles son las principales consecuencias o efectos que esta pandemia ha provocado en las relaciones de familia, en el derecho de familia y en la justicia de familia.

En este último caso, un tema fundamental es el acceso a la justicia de familia de grupos vulnerables, especialmente para las personas que están siendo víctimas de violencia dentro del entorno familiar, situación que sin duda se agudiza por la cuarentena obligatoria y las restricciones a la libertad ambulatoria.

En este trabajo, nos referiremos a distintos tópicos que afectan el derecho de familia, partiendo por el acceso a la justicia de familia en tiempos de la COVID-19, y luego abordaremos el impacto en las relaciones de familia, principalmente los efectos en la relación directa y regular, en las pensiones de alimentos y respecto a la violencia intrafamiliar.

\section{COVID-19 Y ACCESO A LA JUSTICIA DE FAMILIA}

Durante el confinamiento obligatorio, se ha dificultado el funcionamiento de los tribunales de justicia, por una parte, porque se ha restringido la circulación de los ciudadanos y, por otra, por la necesidad de evitar la aglomeración de personas y de esa forma reducir las posibilidades de contagio. En este escenario se suspendieron las audiencias y comparendos, y los tribunales han mantenido una actividad limitada.

Si bien en Chile no se ha decretado feriado judicial, los tribunales se mantienen funcionando, pero solo para causas urgentes. Es decir, aquellas en que exista peligro para la integridad física o psicológica de las personas. En tal sentido, existen diversas dificultades para la revisión judicial de las causas de familia, ya que no es posible realizar las audiencias de manera presencial en el tribunal, por lo que se ha debido recurrir a los medios tecnológicos, lo que representa ciertas exigencias de entrada que pueden terminar limitando el acceso a la justicia a quienes se encuentran en una situación más precaria y que no tienen acceso a internet o a una conexión que les permita participar activamente en las audiencias.

En consecuencia, existen varias trabas para acceder a la justicia en tiempos de pandemia, en especial para temas tan sensibles como los relacionados con la familia. La primera de ellas se refiere a la restricción para tramitar causas que tengan efectivamente algún problema para la salud o la integridad de las personas.

Como segunda traba podemos mencionar que existe un gran número de causas acumuladas, considerando el tiempo en que no han podido funcionar los tribunales, por 
lo cual se estima un retraso considerable y la prolongación de su solución en el tiempo, y la única proyección a corto plazo es retomar las audiencias a través de plataformas de videoconferencia como Zoom o Webex (Poder Judicial de la República de Chile, 2020).

Las primeras audiencias no se han desarrollado libres de dificultades, especialmente en las causas más complejas, como las audiencias de juicio, en las que se debe rendir prueba viva, es decir, la declaración de testigos, peritos o partes. Las dificultades principalmente están relacionadas con las garantías de un debido proceso cuando el testimonio puede ser en cierta forma orientado o influido por terceros, ya que las plataformas de videoconferencia no garantizan que se respeten las condiciones mínimas en la incorporación de la prueba.

Una tercera traba tiene que ver con la mediación, ya que en Chile existen diversas materias de familia en las que se debe acreditar haber cumplido con el proceso previo y obligatorio de mediación. Entre las causas se encuentran la relación directa y regular, las pensiones de alimentos y el cuidado de los hijos. En tal sentido, se estima que no es posible llegar a un acuerdo a través de sistemas virtuales y no es posible realizar el proceso de mediación a través de las nuevas tecnologías, por lo que tampoco se podrá iniciar un juicio de familia en los casos en que la mediación es previa y obligatoria y, por lo tanto, un requisito de admisibilidad de la demanda, lo que en consecuencia representa una barrera importante de acceso a la justicia.

\section{EL IMPACTO EN LAS RELACIONES DE FAMILIA}

El confinamiento impuesto ha afectado las distintas esferas de la vida humana y ha obligado a los ciudadanos a permanecer en sus domicilios sin poder realizar sus actividades habituales, como asistir al colegio, trabajar y participar en reuniones sociales y en encuentros culturales y deportivos.

Por una parte, la restricción a la libertad ambulatoria ha impedido el desarrollo normal de las relaciones paterno filiales, y ha aumentado el número de casos de violencia intrafamiliar; y, por otra, la disminución de la actividad productiva y de servicios ha generado un aumento de la cesantía, la suspensión -en muchos casos- de la relación laboral y la quiebra de varias empresas, con el consecuente impacto en las pensiones alimentarias.

A continuación, vamos a analizar los temas planteados, ya que son de gran importancia social para el desarrollo de las familias.

\section{Relación directa y regular y confinamiento}

La mantención de la relación directa y regular en tiempos del COVID-19 se ha visto dificultada, ya que el confinamiento obligatorio impide mantener el vínculo entre el padre o 
la madre que no tiene el cuidado personal o la custodia y su hijo, en parte por las restricciones para los ciudadanos para salir de su domicilio y en parte por el evidente riesgo de contagio del virus.

Es necesario señalar que la pandemia no necesariamente debe ser considerada una hipótesis de caso fortuito o fuerza mayor que habilite para suspender el régimen comunicacional por un cambio en las circunstancias. Ello dependerá del riesgo concreto que pueda resultar para la salud de los intervinientes o de las consecuencias en cada uno de estos y particularmente en la salud de los niños.

En este sentido, el cambio de circunstancias dependerá de si existe o no un riesgo concreto para la salud de los niños; no es un impedimento per se para mantener el vínculo entre el padre o la madre y el hijo. Este cambio de circunstancias puede habilitar para revisar vía demanda de modificación de relación directa y regular o para modificar los acuerdos que los padres tengan sobre esta materia.

Desde ese punto de vista, lo importante es que ambos progenitores lleguen a acuerdos para definir cómo se materializará el vínculo paterno filial en la situación de confinamiento obligatorio, buscando preservar el vínculo entre progenitores no custodios e hijos y manteniendo las medidas de seguridad para evitar riesgos en la salud de los niños. En tal sentido, las alternativas para mantener el vínculo por medios virtuales, como las videollamadas por WhatsApp o las plataformas de videoconferencia, se presentan como un espacio seguro para preservar el vínculo en los casos en que el régimen comunicacional no se pueda desarrollar de forma presencial (Lepin, 2020).

En ningún caso la pandemia es un obstáculo para dirigirse a buscar a los hijos de manera segura al domicilio donde viven con el padre o la madre que está a su cuidado y llevarlos a otro domicilio. Máxime si el padre o la madre que tiene el cuidado personal realiza actividades fuera del hogar, lo que en el fondo genera una situación de riesgo.

La idea, en definitiva, es minimizar el riesgo concreto para la salud de los niños y permitir que se desarrolle la relación directa y regular, y que solo en los casos en que no sea posible por tratarse de niños con enfermedades de base (por ejemplo, enfermedades respiratorias o graves) será necesario modificar transitoriamente el régimen de visitas y privilegiar las alternativas que la tecnología nos entrega.

\section{Pandemia y pensiones de alimentos}

En términos similares a los señalados, la pandemia no necesariamente va a significar un cambio de las circunstancias que permita modificar las pensiones de alimentos reguladas 0 acordadas por los progenitores. Ello se tendrá que analizar en concreto.

La pandemia, en este aspecto, trae consecuencias graves. Solo por considerar un dato, en Chile aumentó la cesantía en los últimos tres meses del $7 \%$ al $15 \%$, y eso sin 
considerar las medidas económicas que tomó el Gobierno en cuanto a dar la posibilidad a las empresas de suspender la relación laboral por un plazo de tres meses. En consecuencia, si sumamos los casos en los que se suspendió la relación laboral más los casos de cesantía, llegaríamos a un porcentaje superior al 30 \% de personas que se han visto afectadas laboralmente y con una baja parcial o total de sus ingresos.

Esta situación, sin duda, afectará las pensiones de alimentos, lo que se traducirá en demandas de cese o de rebaja de aquellas. En ningún caso una baja en los ingresos o la cesantía habilitan para dejar de pagar de un día para otro los alimentos, ya que en Chile -y en la mayoría de los países- están amparados por un acuerdo o una sentencia aprobada por el tribunal que tiene el valor de cosa juzgada, y para su modificación será necesario iniciar un juicio en el cual se podrá pedir la suspensión, rebaja o cese de la pensión de alimentos, teniendo como fundamento el cambio en las circunstancias económicas como consecuencia de la pandemia que afectan directamente al alimentante.

En el caso de suspensión de la relación laboral, no necesariamente afectará las pensiones de alimentos reguladas, dado que se trata de una situación transitoria por un plazo de tres meses, y luego de transcurrido ese tiempo se retomará la relación laboral con el mismo ingreso que se tenía antes de la suspensión. Por lo tanto, no parece justificada una rebaja o cese de la pensión de alimentos. Habrá que observar el caso concreto para evaluar si el alimentante se ve afectado por la pandemia en cuanto a sus ingresos y si la situación es de carácter permanente, para que pueda considerarse un cambio de circunstancias que permita alterar lo resuelto o lo acordado por las partes.

\section{Violencia intrafamiliar y confinamiento obligatorio}

Por último, en cuanto a la violencia intrafamiliar, según estadísticas proporcionadas por la Organización Mundial de la Salud (OMS), han aumentado en un 70 \% las llamadas a los números de emergencia por situaciones de violencia contra las mujeres y los niños en los distintos países miembros (DW, 2020).

La situación de violencia doméstica no es un tema nuevo. Más bien se trata de un problema grave que afecta a gran parte de la población mundial y que se ha visto agudizado por una serie de factores derivados de la pandemia, entre los cuales se encuentran la cesantía o disminución de los ingresos, la situación de confinamiento obligatorio, las sensaciones de angustia y temor, y la situación de hacinamiento en que viven los sectores más modestos de la sociedad.

Esta grave situación se debe considerar, y otorgar acceso a la justicia de familia a las personas que están siendo víctimas de violencia. Se han de adoptar por parte del Estado todas las medidas de prevención necesarias y asegurar a las víctimas la posibilidad de contar con asesoría letrada para poder ser representadas en juicio y lograr los resultados que permitan sancionar a los responsables. 
En tal sentido, la representación es imprescindible, ya que es necesario que se dicten las resoluciones o medidas cautelares para la protección de las víctimas y, por sobre todo, que se realice un seguimiento a dichas medidas para que, efectivamente, se puedan cumplir y que las personas que se hallan en esta complicada situación no corran riesgos en cuanto a su integridad física o psíquica.

\section{CONCLUSIONES}

El coronavirus ha afectado todas las esferas de la vida humana, como las relaciones interpersonales $y$, especialmente, las relaciones familiares en los aspectos ya analizados, y en otros más que seguramente se van a manifestar con el transcurso del tiempo. Sin duda, el confinamiento obligatorio y las restricciones a la libertad individual inciden de forma directa en las relaciones de familia, ya que al limitar su desplazamiento se ven afectadas las relaciones paterno filiales y, por otro lado, la posibilidad de contagio del virus genera factores de riesgo respecto a la salud de los intervinientes. En el mismo sentido, dichas situaciones se transforman en factores de riesgo para las víctimas de violencia intrafamiliar, que viven los abusos encerradas con sus agresores.

\section{REFERENCIAS}

DW. (8 de mayo del 2020). OMS confirma aumento de violencia contra mujeres por cuarentenas. Recuperado de https://www.dw.com/es/oms-confirma-aumentode-violencia-contra-mujeres-por-cuarentenas/a-53366780

Lepin, C. (2020). La pandemia COVID-19 y sus efectos en las relaciones de familia. En C. Lepin (Dir.), Caso fortuito fuerza mayor. Estudios a partir de la pandemia del COVID-19 (pp. 99-106). Valencia: Tirant Lo Blanch.

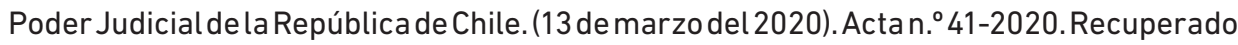
de https://www.pjud.cl/documents/396588/0/acta+41-2020+teletrabajo.pdf/35 f724db-8c29-47ee-bac9-6846e24257ad

\section{BIBLIOGRAFÍA}

Dirección del Trabajo. (25 de marzo del 2020). ¿El empleador que se encuentra imposibilitado de funcionar con su empresa por el coronavirus puede suspender en forma unilateral la relación laboral? Recuperado de https://www.dt.gob.cl/ portal/1628/w3-article-118440.html

El Mostrador. (30 de junio del 2020). Efecto COVID-19: desempleo llega a un histórico 11,2\% en todoChile. Recuperado de https://www.elmostrador.cl/dia/2020/06/30/ efecto-covid-19-desempleo-llega-a-un-historico-112-en-todo-chile/ 
Lepin, C. (2017). Derecho familiar chileno. Santiago de Chile: Thomson Reuters.

Lepin, C. (2019). Código de derecho familiar. Santiago de Chile: Editorial Hammurabi.

Lepin, C. (2020). Relación directa y regular en tiempos de COVID-19. Diario Jurisprudencial (2). Recuperado de https://latam.tirantonline.com/latam/

Lepin, C. y Ravetllat, I. (2020). COVID-19 y derecho de familia. Valencia: Tirant Lo Blanch.

Medina, G. (9 de abril del 2020a). Familia y coronavirus. 10 claves para comprender su relación jurídica. La Ley, LXXXIV (66), 2-3.

Medina, G. (13 de abril del 2020b). COVID-19, el deber de cuidado y el derecho de comunicación de hijos, progenitores y familiares. La Ley, LXXXIV (67), 1-5.

Meinz, E. (mayo del 2020). Impacto del COVID-19 en la economía de América Latina y Chile. Recuperado de http://www.flacsochile.org/slider/articulo-impacto-del -covid-19-en-la-economia-de-america-latina-y-chile/ 